\title{
Constitucionalización de los derechos laborales a través del desarrollo jurisprudencial en el caso de la estabilidad laboral y ocupacional reforzada
}

\author{
Constitutionalizing Labor Rights through Jurisprudential Development \\ in the Case of Reinforced Labor and Occupational Stability \\ Constitucionalização dos direitos trabalhistas por \\ meio do desenvolvimento jurisprudencial no caso da \\ estabilidade laboral e ocupacional reforçada
}

Javier EduARdo AlmanZa JunCO*

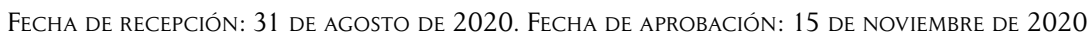

Doi: https://doi.org/10.12804/revistas.urosario.edu.co/sociojuridicos/a.10026

Para citar este artículo: Almanza Junco, J. E. (2021). Constitucionalización de los derechos laborales a través del desarrollo jurisprudencial en el caso de la estabilidad laboral y ocupacional reforzada. Revista de Estudios SocioJurídicos, 23(1), 7-33. https://doi.org/10.12804/revistas.urosario.edu.co/sociojuridicos/a.10026

\section{RESUMEN}

El presente artículo estudia el fenómeno de la constitucionalización de los derechos laborales en el caso puntual del desarrollo y configuración de la denominada figura de la estabilidad laboral reforzada, hoy extendida a estabilidad ocupacional reforzada. Para lo anterior, se identifica justificada la relación que ha tenido esta institución del derecho laboral, derivada del principio constitucional de la estabilidad en el empleo, con la configuración y desarrollo de los distintos fueros laborales de origen normativo y jurisprudencial. En consecuencia, se establece que, sobre la base del desarrollo jurisprudencial de cada uno de los fueros, se ha logrado dotar de eficacia jurídica a estas estabilidades laborales y ocupacionales reforzadas. Todo lo anterior ocurre en medio del trasegar histórico de una Corte Constitucional que, desde su creación, cada vez se ha ido afianzado más a la denominada práctica del desarrollo progresivo en materia de derechos fundamentales, cuyo contenido analítico y práctico genera una legitimidad consistente en el resultado institucional, al amparo de la praxis del nuevo constitucionalismo en el marco de los Estados constitucionales de derecho.

* Profesor del posgrado Derecho Laboral y de la Seguridad Social de la Universidad Católica de Colombia. Correo electrónico: Jealmanza@ucatolica.edu.co 
Palabras clave: constitucionalización de los derechos; estabilidad laboral; estabilidad laboral reforzada; estabilidad ocupacional reforzada; fuero laboral.

\section{ABSTRACT}

This article studies the phenomenon of the constitutionalizing of labor rights in the specific case of the development and configuration of the so-called figure of reinforced labor stability, today extended to reinforced occupational stability. For the above, the relationship that this institution of labor law has had, derived from the constitutional principle of job stability, with the configuration and development of the different labor laws of normative and jurisprudential origin, is justified. Consequently, it is established that, based on the jurisprudential development of each of the jurisdictions, these reinforced labor and occupational stabilities have been endowed with legal effectiveness. All of the above occurs in the midst of the historical transfer of a Constitutional Court that, since its creation, has become increasingly entrenched in the so-called practice of progressive development in the area of fundamental rights, whose analytical and practical content generates a consistent legitimacy in the institutional result, under the protection of the praxis of the new constitutionalism within the framework of constitutional states of law.

Keywords: Constitutionalizing of rights; job stability; reinforced job stability; reinforced occupational stability; judicial labor guarantee.

\section{RESUMO}

Este artigo estuda o fenômeno da constitucionalização dos direitos trabalhistas no caso específico do desenvolvimento e configuração da chamada figura da estabilidade profissional reforçada, hoje estendida à estabilidade ocupacional reforçada. Pelo exposto, justifica-se a relação que esta instituição do direito do trabalho tem mantido, derivada do princípio constitucional da estabilidade do emprego, com a configuração e desenvolvimento das diferentes legislações laborais de origem normativa e jurisprudencial. Consequentemente, verifica-se que, com base no desenvolvimento jurisprudencial de cada uma das jurisdições, essas estabilidades laborais e ocupacionais reforçadas foram dotadas de eficácia jurídica. Tudo isso se dá em meio a trajetória histórica de um Tribunal Constitucional que, desde sua criação, tem se enraizado cada vez mais na chamada prática de desenvolvimento progressivo na área dos direitos fundamentais, cujo conteúdo analítico e prático gera uma legitimidade consistente no resultado institucional, sob a proteção da práxis do novo constitucionalismo dentro do marco dos Estados constitucionais de direito.

Palavras-chave: constitucionalização de direitos; estabilidade do emprego; estabilidade reforçada do emprego; estabilidade ocupacional reforçada; jurisdição trabalhista. 


\section{Introducción}

Con la expedición de la Constitución Política de 1991 (Const.), Colombia abrió camino a un nuevo escenario del contrato social, entendido bajo el paradigma de un Estado social de derecho que se enuncia expresamente desde su primer artículo. Bajo la óptica de una armonía constitucional, se puede identificar que, en el planteamiento de los artículos siguientes y las normas que los desarrollan, se ha buscado la formulación de preceptos normativos por medio de los cuales se pueda lograr cada vez una mejor configuración y materialización de este Estado social de derecho.

La Constitución así se puede comprender como un texto vivo, el cual busca ser actualizado e interpretado conforme a las dinámicas y realidades vistas en la cotidianidad y las circunstancias particulares de las personas y demás actores que interactúan en medio del contrato social. La actualización, vía reforma constitucional, le compete exclusivamente al poder legislativo; de otra parte, la interpretación, vía sentencia o precedente judicial, reposa por lo general en el poder judicial, desde el que se puede reconocer una participación destacada de la Corte Constitucional (Jaramillo, 2012).

Esta corporación, creada con ocasión de la entrada en vigor de la Constitución Política de 1991, tiene como gran mandato constitucional, enunciado desde el propio Texto Superior, el de guardar la integridad y supremacía de la Constitución (Const., artículo, 241), para lo cual se le han asignado unas funciones específicas, incluidas no solo en los numerales que desarrollan este artículo 241, sino también conforme a lo dispuesto en los artículos 239 a 245, dejando, entre otros resultados, la aplicación de la denominada institución de la cosa juzgada material ${ }^{1}$ (Nisimblat, 2009).

Explica la Corte Constitucional que, "[l]a cosa juzgada constitucional es una institución jurídica procesal, que tiene su fundamento en el artículo 243 de la Constitución Política, mediante la cual se otorga a las decisiones plasmadas en una sentencia de constitucionalidad, el carácter de inmutables, vinculantes y definitivas". (Sentencia C-587, 2014). Luego, se aprecia que es precisamente un tránsito a cosa constitucional juzgada lo que se ha dado con ocasión de la constitucionalización de derechos laborales innominados, como sucede en el caso del derecho a la estabilidad ocupacional reforzada, cuya caracterización se genera a partir de una interpretación más amplia y comprehensiva de lo que en sentido estricto se entiende por el 
Se puede establecer que, con ocasión de lo desarrollado en la jurisprudencia para las figuras de la estabilidad laboral y ocupacional reforzada, existe una cosa juzgada material constitucional a la que pueden apelar los administrados quienes se encuentren en una condición laboral especial de protección constitucional. El objeto del actual documento es la exposición analítica de cómo se ha dado este desarrollo, generando su explicación desde el soporte conceptual y teórico de la denominada constitucionalización del derecho, la cual se considera columna hermenéutica de su construcción sociojurídica.

\section{Constitucionalización del derecho}

Identificar la Constitución Política de Colombia de 1991 como un texto vivo sugiere un tránsito constitucional que supera la rigidez de la anterior Constitución (1886); esta rigidez, es comparable con el derecho formalista y estatista característico del Estado de derecho legal (Vigo, 2012). En su explicación, Vigo (2012) resalta que, en el tránsito de este Estado de derecho legal a un Estado de derecho constitucional, la Constitución, como fuente angular del orden jurídico, desarrolla su contenido sobre la base de principios y la reivindicación de los derechos humanos, configurando en este sentido cuatro rasgos centrales de este Estado de derecho constitucional, a saber:

a) la Constitución deja de ser un programa político dirigido al legislador y se convierte en una fuente del derecho a la que los juristas pueden ir a buscar las respuestas jurídicas que plantean los problemas de los que se ocupan; b) la Constitución en su totalidad se convierte en una norma jurídica eficaz, en el sentido que no hay normas meramente programáticas en tanto todas ellas "operan" aun cuando se constaten distintos modos de operatividad, pero no hay normas constitucionales que carezcan de efectos o vigencia; c) con la prevención que hacía Kelsen, las Constituciones se cargan de valores

\footnotetext{
derecho a la estabilidad ocupacional reforzada (Sentencia T-881 de 2012), la cual, a su vez, se desprende de la abstracción interpretativa de la "estabilidad en el empleo", entendida como uno de los principios enunciados en el artículo 53 del Texto Constitucional.
} 
o de moral, y así el interés central de las mismas ya no en sus partes "orgánicas" sino las "dogmáticas" y; d) se establecen los controles judiciales de constitucionalidad, o sea surgen jueces con competencia para que en el nombre del poder constituyente tengan la última palabra como para llegar a invalidar lo decidido legislativamente por la "voluntad general" (p. 60).

En consecuencia, la actividad del juez constitucional, en cabeza de la Corte Constitucional para el caso colombiano, se formula y legitima con ocasión de la posibilidad de hacer eficaz y vigente el contenido del Texto Constitucional, con un alcance que vitaliza la realización efectiva de su contenido. Al ser la Corte Constitucional un órgano colegiado de debate y decisión, se espera que, en el seno de su actividad judicial, se produzcan los más rigurosos debates y análisis por medio de los cuales se logre la mejor interpretación posible de los temas que se discuten en función de los reclamos de justiciabilidad hechos por los administrados, quienes buscan, por ejemplo, bajo ciertas actuaciones, que esta corporación analice la constitucionalidad de diferentes preceptos normativos.

También, a través de sus decisiones y pronunciamientos, este tribunal busca establecer los alcances de aquella justicia no evidente en el ordenamiento jurídico nacional. Esto es lo que precisamente ha sucedido en varias de las situaciones en materia laboral, donde se ha logrado la constitucionalización de derechos vía sentencia constitucional, toda vez que el alcance, por ejemplo, de algunos fueros laborales o reconocimiento de estabilidades laborales reforzadas no se encuentra explícitamente enunciado en norma alguna, sino que hay un cúmulo de sentencias por medio de las cuales se ha determinado su contenido y alcance.

En este sentido, al mencionar la constitucionalización del derecho se está apelando a reconocer una actividad hermenéutica del juez constitucional que, en el marco de sus funciones constitucionales, se ha asentado en la naturaleza del Texto Constitucional y el espíritu del constituyente derivado para identificar la configuración de derechos innominados, los cuales merecen el reconocimiento a grado constitucional (Alexy, 2013); toda vez que una acción contraria se opondría a la materialización armónica del contenido de la Norma Superior, lo cual, en consecuencia, llevaría a una degradación de la vitalidad de una constitución como la colombiana. 
Lo anterior se ha dado en el marco de lo que se ha identificado como una actividad judicial de carácter progresista por parte de la Corte Constitucional (Fajardo \& Guataquí, 2000) que, en materia laboral, permite reconocer una constitucionalización de los derechos laborales para asuntos precisos como el de la denominada estabilidad ocupacional reforzada, extensión de la estabilidad laboral reforzada, cuyos criterios de caracterización y aplicación en la actualidad resultan del desarrollo jurisprudencial hecho en la materia.

Como lo identifica Rodolfo Vigo (2012), el denominado neoconstitucionalismo, o la constitucionalización del derecho, se encuentra en la base de lo que permite fijar la legitimidad de este desarrollo progresivo desde la jurisprudencia constitucional en una interpretación que resulta clave en la comprensión de la constitucionalización de los derechos laborales y su aplicación precisa en el caso de la estabilidad laboral y ocupacional reforzada, frente a lo cual se avanza en la siguiente sección del documento.

\section{Fueros laborales: algunas nociones de su constitucionalización como derecho fundamental}

Se ha indicado que el artículo constitucional 53 establece los denominados principios mínimos fundamentales del derecho laboral colombiano, entre estos, el de estabilidad en el empleo. De entrada, el principio en sí, enunciado en abstracto, puede presentar más inquietudes que certezas; de allí lo relevante de su interpretación constitucional en cabeza de la Corte Constitucional, quien desde sentencias tempranas ha definido que esta estabilidad en el empleo, a título de principio, no hace referencia al abstracto de permanencia indefinida en un empleo, sino a la de establecer en el contrato de voluntades entre el empleador y el empleado, condiciones para que este último "goce de una certeza mínima en el sentido de que el vínculo laboral contraído no se romperá de manera abrupta y sorpresiva" (Sentencias C-016, 1998). ${ }^{2}$ 
Lo anterior, podría llevar a suponer que todo contrato de trabajo celebrado bajo el ordenamiento jurídico colombiano se encuentra fijado sobre la base de una relación laboral, la cual no contemple forma alguna de despido imprevisto por parte del empleador al margen de lo fijado en el contrato de trabajo, afirmación que no es en estricto cierto, toda vez que, bajo ciertas circunstancias, se puede reconocer en algunos casos la legalidad del despido, incluso sin justa causa, caso en el cual esta procede siempre y cuando al trabajador afectado por la decisión se le reconozca una indemnización compensatoria por la cesación imprevista del acuerdo laboral pactado.

Frente a este escenario, es relevante destacar que no todas las relaciones laborales son susceptibles de poder ser legalmente finalizadas sin justa causa, incluso cuando se ofrezca o se pague una indemnización para su cometido, esta se debe efectuar con la autorización adicional de la Inspección del Trabajo, pues de lo contrario el despido puede carecer de eficacia. Sirva como ejemplo mencionar lo que sucede en el caso del fuero circunstancial ${ }^{3}$ que, analizado en Sentencia de Unificación 432 de 2015, la Corte Constitucional reitera la jurisprudencia al respecto consolidada, donde se insiste en la ineficacia del despido para el caso de este fuero si no se consolida una causal objetiva para su realización.

La Corte, en la jurisprudencia mencionada, recuerda el cambio en el precedente judicial en la materia fijado por la Corte Suprema de Justicia, Sala Laboral, que desde 1998 modificó el criterio que venía fijado desde 1986, que aceptaba la indemnización como medio resolutivo del conflicto laboral sucedido con ocasión del trabajador despedido, mientras se desarrollaba un pacto colectivo, sin que existiera causal objetiva para generar su despido, concluyendo en este sentido que, el "desconocimiento del fuero circunstancial da lugar a la ineficacia del despido, el reintegro del trabajador y el pago de salarios y prestaciones dejados de percibir por el afectado" (su-432 de 2015).

Lo visto en la aplicación del fuero circunstancial se puede reconocer en la generalidad de los fueros laborales para ciertos trabajadores, cuya

3 El fuero circunstancial es una figura definida en el artículo 25 del Decreto 2351 de 1965, a través del cual se protege al trabajador sindicalizado o no sindicalizado, para que no sea despedido cuando se presenta un pliego de peticiones. La vigencia del fuero es desde que se presenta el mencionado pliego hasta el arreglo del conflicto. 
configuración a título de derecho fundamental, se regla por los siguientes elementos esenciales: i) el derecho a conservar el empleo; ii) el derecho a no ser despedido por la situación de vulnerabilidad o debilidad manifiesta; iii) a permanecer en el empleo hasta que se requiera y siempre que no se configure una causal objetiva que conlleve la desvinculación, y iv) que cualquier desvinculación se dé con la autorización expresa de la autoridad laboral competente, bajo la verificación de una causal objetiva no relacionada con la situación de vulnerabilidad o debilidad manifiesta del trabajador (Sentencia C-200, 2019).

Este orden esencial en el respeto de la garantía del derecho a la estabilidad laboral reforzada, como derecho fundamental, compromete además normas de derecho internacional que vinculan al Estado colombiano, para citar tan solo uno de los instrumentos vinculantes se puede mencionar la Convención Americana sobre Derechos Humanos (CADH). En el caso de la Corte Interamericana de Derechos Humanos (Corte IDH), quien observa y juzga sobre asuntos contenidos en la $\mathrm{CADH}$, en la Sentencia del caso Lagos del Campo c. Perú de 2017, esta estableció respecto a la garantía fundamental de la estabilidad laboral reforzada lo siguiente:

la estabilidad laboral no consiste en una permanencia irrestricta en el puesto de trabajo, sino de respetar este derecho, entre otras medidas, otorgando debidas garantías de protección al trabajador a fin de que, en caso de despido se realice este bajo causas justificadas, lo cual implica que el empleador acredite las razones suficientes para imponer dicha sanción con las debidas garantías, y frente a ello el trabajador pueda recurrir tal decisión ante las autoridades internas, quienes verifiquen que las causales imputadas no sean arbitrarias o contrarias a derecho.

La sentencia mencionada es paradigmática en términos del asunto estudiado, toda vez que se trata de una sentencia que genera por primera vez una responsabilidad internacional de un Estado en relación con la estabilidad laboral reforzada para el Sistema Interamericano de Derechos Humanos. Se resalta de la sentencia la manera como califica la estabilidad laboral reforzada en términos de una protección que brinda 
al trabajador una expectativa cierta y fundada sobre las condiciones de tiempo y lugar en medio de las cuales debe desarrollar la actividad para la cual fue contratado sin que pueda ser despedido, sin causal objetiva diferente a la de su fuero.

Para el caso colombiano, en armonía con lo dictado por la Corte IDH, se ha definido que la estabilidad laboral reforzada cuenta con un refuerzo de garantía constitucional que lo proyecta a título de derecho fundamental. Así las cosas, la figura de la estabilidad laboral reforzada ha contado en algunos casos con un despliegue legislativo, aunque, en otros, ante la ausencia de acciones legislativas en la materia, ha sido la Corte Constitucional la que se ha abocado la tarea de identificar y caracterizar sus condicionales y alcances no previstos en disposiciones normativas.

Frente a los fueros laborales de origen normativo o legislativo sirva mencionar el fuero por acoso laboral, dispuesto en el artículo 11 de la Ley 1010 de 2006, el cual protege al trabajador que interponga una queja, petición o denuncia por acoso laboral o a quienes sirvan de testigos de estas conductas, siempre y cuando se evidencie la ocurrencia de los hechos. Si bien frente a este fuero han servido los pronunciamientos constitucionales para definir en cierto sentido su alcance, la base normativa por medio de la cual se ha dado su reconocimiento, en principio, ha resultado suficiente para lograr su tutela.

De otra parte, el fuero sindical, reconocido de conformidad con lo dispuesto en los artículos 405 y siguientes del Código Sustantivo del Trabajo (CST), que protege a los trabajadores sindicalizados para que estos no sean despedidos en las condiciones previstas para el ya mencionado caso del denominado fuero circunstancial, hace parte de los fueros de origen legislativo, frente a los cuales los pronunciamientos jurisprudenciales tanto de la Corte Constitucional como de la Corte Suprema de Justicia, en su Sala Laboral, que han sido claves en el objeto de su reivindicación.

Igual sucede en el caso del fuero de salud, definido en el artículo 26 de la Ley 361 de 1997, cuyo desarrollo jurisprudencial ha llevado a su conceptualización más ampliada de fuero de indefensión o fuero aplicable a las personas en circunstancias de debilidad manifiesta que tengan una afectación en su salud (su-049, 2017). Tránsito similar es 
el que ha logrado el fuero de maternidad definido en el artículo 239 del CST, cuyo desarrollo jurisprudencial ha permitido su extensión y determinación de un mayor alcance tanto para situaciones propias del embarazo de la madre, el periodo de lactancia o la pareja de la mujer embarazada.

El caso del fuero por maternidad permite introducir un concepto clave adicional en materia de la hermenéutica jurídica que subyace a esta denominada constitucionalización de los derechos, que corresponde a la acción de la Corte Constitucional por omisión legislativa relativa. Explica la Corte que, frente a ciertas situaciones, puede que exista una omisión legislativa absoluta, allí es cuando la Corte exhorta a este poder a legislar sobre el tema. No obstante, en otros casos, como el que se quiere precisar del fuero maternal, en el que ya existe una base legislativa de desarrollo, el remedio no debe ser declarar la inexequibilidad, sino neutralizar la deficiencia de su alcance, como se hace en la Sentencia C-005 de 2017, donde se extiende la estabilidad laboral reforzada a la pareja de la mujer embarazada o lactante no trabajadora:

esta Corporación ha admitido, con fundamento en el principio democrático, que cuando se encuentra ante una omisión legislativa relativa "es competente para incorporar un significado ajustado a los mandatos constitucionales por medio de una sentencia integradora en la que se declare la exequibilidad condicionada del precepto acusado, en el entendido de que este debe además comprender aquellos supuestos que fueron indebidamente excluidos por el Legislador". La sentencia C-584 de 2015 reiteró lo afirmado por esta Corporación en la C-619 de 2011, que indicó: "[p]or regla general, cuando se trata de una omisión legislativa relativa, el remedio para la inconstitucionalidad advertida no es la declaratoria de inexequibilidad de la disposición que dejó por fuera de sus efectos jurídicos el elemento que se echa de menos, sino neutralizar dicho efecto contrario a la Constitución mediante la incorporación de un significado ajustado a los mandatos constitucionales" (Sentencia C-005, 2017).

Sea entonces este ejercicio constitucional una de las maneras como se puede evidenciar el efecto de la constitucionalización de los derechos laborales, en el sentido de que no solo se resuelve una insuficiencia 
normativa, sino que esta se justifica en la necesidad de armonizar la disposición estudiada con el orden constitucional que, de modo contrario - declarar la inexequibilidad-, llevaría a una mayor profundización de la inconsistencia existente entre la norma y los principios y las reglas constitucionales. Esto, por ejemplo, también sucede en el caso del fuero prepensional o de persona próxima a adquirir el estatus pensional, cuya definición normativa en principio estaba pensada para ciertos empleados del sector público, pero que, en consideración de la Corte, se concluyó que debía ser también una prerrogativa extensible a los trabajadores del sector privado (Sentencia T-357, 2016).

Las menciones anteriores permiten introducir algunas modificaciones constitucionales que han tenido los distintos fueros laborales desde la jurisprudencia, reconociendo para la diversidad de casos un rol altamente participativo de la Corte Constitucional, cuyo dimensionamiento de la naturaleza y alcance de esta figura ha permitido estructurar una sólida configuración de los fueros laborales en el ordenamiento jurídico colombiano. En la siguiente sección del documento se vuelve sobre algunos de los fueros mencionados, para revisar el particular del tránsito de la figura de la estabilidad laboral a la estabilidad ocupacional reforzada, como una clara ejemplificación de esta constitucionalización de los derechos no solo laborales sino ocupacionales.

\section{La estabilidad laboral reforzada y la estabilidad ocupacional reforzada en la jurisprudencia constitucional}

Conforme a lo previamente visto, se establece que la estabilidad laboral reforzada es una figura de origen normativo, cuya naturaleza se estableció en principio en la protección del trabajador del despido por una situación de vulnerabilidad, hoy también comprendida por una situación de debilidad manifiesta temporal o permanente. El alcance que tiene esta protección, en conexidad con otros derechos fundamentales, es que se le ha otorgado a esta figura el grado de derecho fundamental, cuya extensión resulta más amplia de lo inicialmente señalado en las normas que la regulan, en un proceso que ha sucedido a través de la actividad jurisprudencial de la Corte Constitucional. 
Se puede indicar que, en la actualidad, el fuero laboral es la institución jurídica por medio de la cual se materializan la estabilidad laboral y ocupacional reforzada para ciertos trabajadores en el sistema laboral colombiano, incluso cuando estos no cuenten en estricto sentido con un contrato de trabajo. Un primer caso paradigmático en este sentido ocurre con ocasión de la extensión del derecho fundamental a la estabilidad laboral reforzada de quienes se encuentran en circunstancias de debilidad manifiesta o indefensión, como quienes cuentan con un contrato de aprendizaje, como se señala en la Sentencia T-881 de 2012 de la Corte Constitucional

Para este caso, la manera como el alto tribunal constitucional extiende de manera analógica el derecho a la estabilidad laboral reforzada de los trabajadores al caso de los aprendices, que de acuerdo al CST tienen un contrato especial de trabajo denominado contrato de aprendizaje, permite entrever la labor de la Corte Constitucional en la vía de ir más allá de lo expresamente señalado en la norma, para ajustar diferentes preceptos normativos a condiciones más armónicas con el ordenamiento constitucional, ampliando en este sentido el alcance de aplicabilidad de una norma que, en su interpretación exegética, no les permite a ciertos trabajadores acogerse a este fuero.

Dentro del análisis constitucional hecho para su extensión no solo se contempla el principio laboral de estabilidad laboral, sino que además la Corte reconoce que, bajo el ordenamiento constitucional colombiano, está la responsabilidad del Estado de promover la integración social de las personas con algún tipo de discapacidad (Const., artículo, 47), a su vez que, encontrando administrados en debilidad manifiesta, es deber del Estado colombiano propender por su especial protección constitucional para que gocen de una igualdad real y efectiva (Const., artículo, 13), además de la obligación a la solidaridad que tienen los demás administrados para con quienes se encuentren en peligro por circunstancias de salud física o mental (Const., artículo, 95).

Lo anterior permite dar una mirada adicional a lo que ha sido esta constitucionalización de los derechos laborales por parte de la Corte Constitucional, cuyo ejercicio no se encuentra fundado en el capricho interpretativo del juez constitucional, sino que atiende a un criterio de justicia en un carácter axiológico que se encuentra más allá del 
paradigma ius positivista de responder a lo expresamente señalado en la norma, estableciendo en este sentido un neoconstitucionalismo basado en el paradigma del Estado de derecho constitucional como se explicó en la primera parte del documento.

Son diversos, en consecuencia, los ejemplos por medio de los cuales se puede acudir a la ejemplificación de esta constitucionalización de los derechos por parte de la Corte Constitucional, que en lo preciso de esta sección se subraya en el tránsito de la estabilidad laboral reforzada a su extensión a la estabilidad ocupacional reforzada; esto, a través de la Sentencia SU-049 de 2017. La SU-049 de 2017 indica que, al ser el principio de estabilidad laboral reforzada una figura que remite nominalmente por regla a las relaciones de trabajo dependiente, se debe hacer mención también a la estabilidad ocupacional reforzada por ser una denominación más amplia y comprehensiva de aquellas relaciones contractuales donde no exista en sentido estricto una relación laboral. De manera puntual esta Corporación señala:

La jurisprudencia constitucional ha usado de forma dominante la expresión "estabilidad laboral reforzada" para hacer alusión al derecho fundamental antes caracterizado. En nuestro medio jurídico, la locución 'laboral' se asocia legislativamente a las relaciones de trabajo dependiente, caracterizadas por la prestación de servicios personales bajo subordinación jerárquica. No obstante, esta Corte ha señalado que el derecho a la estabilidad laboral reforzada aplica no solo a quienes tienen un vínculo de trabajo dependiente estrictamente subordinado y sujeto al derecho laboral, sino también a quienes están insertos en relaciones ocupacionales divergentes, originadas por ejemplo en un contrato de prestación de servicios o en un contrato de aprendizaje (su-049, 2017).

En consecuencia, la referencia a la estabilidad ocupacional reforzada se puede inferir derivada de la interpretación que el juez constitucional hace de, entre otros principios, la estabilidad laboral. Sea relevante destacar por ejemplo que, en la emergencia de esta figura de la estabilidad ocupacional reforzada, su construcción conceptual no se define tan solo a partir de la sentencia previamente mencionada, sino que esta hace 
parte de una construcción discursiva en medio de la actividad del juez constitucional, con antecedentes desde el 2012 conforme a lo señalado en la Sentencia T-881 de ese mismo año.

Esta cualidad de construcción jurídica en el tiempo, que se identifica para esta figura de la estabilidad ocupacional reforzada, es lo que sucede en muchas de las reivindicaciones hechas por la Corte Constitucional no solo en materia laboral, sino también en otras áreas del derecho que trastocan derechos fundamentales. Lo anterior bien puede llevar a reconocer que la actividad judicial de la Corte Constitucional, en relación con la construcción discursiva y armónica de lo que dispuso el Constituyente derivado de 1991 versus las normas que complementan el orden jurídico nacional, se define sobre un diálogo de largo aliento de los jueces constitucionales que dotan de contenido y razón a las interpretaciones que concluyen el contenido y alcance de ciertos derechos.

Así, se puede concluir que la actividad del juez constitucional, estructuralmente una actividad de orden interpretativo y reivindicativo, sucede a tenor de la delegación dada por el constituyente primario a unas personas probas, para que estas analicen, definan e identifiquen cuándo algún precepto normativo dotado de legalidad anula alguna disposición constitucional, momento en el cual se espera como resultado la declaratoria de inconstitucionalidad. También se espera de estos jueces constitucionales que reivindiquen y tutelen derechos cuando, frente a situaciones particulares, se reconozca la ausencia de normas que garanticen la justicia fáctica.

Esto último es lo que se considera ha sucedido en situaciones propias del derecho laboral, caso puntual, la estabilidad ocupacional reforzada que, como se ha explicado, además sucede sobre la base de una construcción discursiva que convoca varias sentencias, entendido lo anterior en algunos casos bajo el denominado criterio de las líneas jurisprudenciales (López, 2006) por medio de las cuales se configura una carga argumental y discursiva que, además en la generalidad de los casos, adquiere un respaldo de las demás ramas del poder, operadores judiciales, la academia y entendidos de los temas tratados, legitimando en este sentido su acción y resultado. 


\section{Conclusiones}

El reconocimiento de la constitucionalización del derecho laboral colombiano que ha llevado, entre otros asuntos, a la construcción jurídica de la denominada institución de la estabilidad laboral y ocupacional reforzada, se realiza desde el análisis de una variedad de sentencias constitucionales, cuyo desarrollo interpretativo permite identificar a un juez constitucional que, en el horizonte de hacer la Constitución Política un instrumento jurídico-institucional dotado de eficacia jurídica, ha reivindicado la institución jurídica de la estabilidad laboral y ocupacional reforzada, legitimando con ello la armonía implícita y explícita que tiene esta con varios de los preceptos enunciados en el Texto Superior.

Se ha logrado identificar el trasegar que ha tenido en sede de la Corte Constitucional la reivindicación jurídica de la figura del fuero laboral, hoy sustento tanto de la aplicabilidad de la estabilidad laboral reforzada, como de la estabilidad ocupacional reforzada. Sobre esta última figura, presta importancia destacar cuál configuración jurídica se debe a la interpretación activa que hace el alto tribunal constitucional, sobre la garantía del principio de estabilidad laboral que no solo aplica al terreno exclusivo de los contratos laborales, sino también a formas contractuales similares en las que se identifique el trato excepcional que se debe dar a ciertas personas para que, a través de esa estabilidad, por conexidad, logren la realización de otros derechos fundamentales.

Lo anterior sucede en el marco de la denominada constitucionalización de los derechos en el ejercicio legítimo de la Corte Constitucional, que bien puede ser interpretado como la capacidad jurídico-institucional con la que cuenta esta corporación para interpretar armónicamente aquello que los constituyentes derivados plasmaron en la Constitución Política de 1991. En la literatura jurídica esto es comprendido como parte de las trasformaciones que ha tenido el derecho constitucional contemporáneo en gran parte de los Estados democráticos del mundo, bautizado con el nombre de neoconstitucionalismo y, entendido como un soporte teórico por medio del cual se legitima la acción propositiva del juez constitucional que se desprende de la metódica lectura exegética de lo dispuesto en el ordenamiento normativo. 
Sobre este horizonte, el Tribunal Constitucional deja de ser un mero instrumento institucional validador de las decisiones del poder ejecutivo y legislativo para ser, por el contrario, de manera activa, quien a través de sus sentencias exhorta a trabajar a los demás poderes en función de lograr la máxima eficacia posible en la materialización de lo dictado en el Texto Constitucional. Esta eficacia se visibiliza, además, en que el Tribunal, al ser consultado por los administrados frente a posibles situaciones de normas del ordenamiento normativo que ahogan el espíritu de la Constitución, actúa desde el análisis constitucional, tomando decisiones por medio de las cuales se logre la mayor armonía jurídica, ponderando siempre como regla principal lo dispuesto en el Texto Superior y las normas que lo complementan vía bloque de constitucionalidad.

\section{Referencias}

Alexy, R. (2013). Los derechos fundamentales en el estado constitucional democrático. En: Carbonell, M. (editor). Neoconstitucionalismo(s), (pp. 31-48). Editorial Trotta.

Colombia, Congreso de la República. Ley 361, Por la cual se establecen mecanismos de integración social de las personas con limitación <en situación de discapacidad $>$ y se dictan otras disposiciones ( 7 febrero 1997).

Colombia, Congreso de la República. Ley 1010, Por medio de la cual se adoptan medidas para prevenir, corregir y sancionar el acoso laboral y otros hostigamientos en el marco de las relaciones de trabajo (23 enero 2006).

Colombia, Corte Constitucional. Sentencia C-016 (4 febrero 1998).

Colombia, Corte Constitucional, Sala Primera. Sentencia T-881 (29 octubre 2012).

Colombia, Corte Constitucional, Sala Plena. Sentencia C-587 (13 agosto 2014).

Colombia, Corte Constitucional, Sala Tercera. Sentencia T-824 (5 noviembre 2014).

Colombia, Corte Constitucional, Sala Plena. Sentencia su-432 (9 julio 2015)

Colombia, Corte Constitucional, Sala Sexta. Sentencia T-357 (6 julio 2016).

Colombia, Corte Constitucional, Sala Plena. Sentencia C-005 (18 enero 2017).

Colombia, Corte Constitucional, Sala Plena. Sentencia su-049 (2 febrero 2017).

Colombia, Corte Constitucional, Sala Plena. Sentencia C-028 (30 enero 2019).

Colombia, Corte Constitucional, Sala Plena. Sentencia C-200 (15 mayo 2019). 
Colombia, Presidencia de la República. Decreto 2351, Por el cual se hacen unas reformas al Código Sustantivo del Trabajo (4 septiembre 1965).

Corte Interamericana de Derechos Humanos. Sentencia, caso Lagos del campo c. Perú (31 agosto 2017). https://www.corteidh.or.cr/corteidh/docs/casos/ articulos/seriec_340_esp.pdf

Fajardo, L., E Guataquí, J. (2000). La Corte Constitucional y la flexibilidad del mercado laboral. Revista de Economía Institucional, 2(3), 80-103.

Jaramillo, J. (2012). Colombia's 1991 Constitution: A Rights Revolution. In: Nolte, D., \& Schilling, A. (eds.). New Constitutionalism in Latin America. Promises and practices, (pp. 313-331). Ashgate Publishing Limited.

López, D. (2006). El derecho de los jueces: obligatoriedad del precedente constitucional, análisis de sentencias y líneas jurisprudenciales y teoría del derecho judicial. Universidad de Los Andes; Legis.

Nisimblat, N. (2009). La cosa juzgada en la jurisprudencia constitucional colombiana y el principio del estoppel en el derecho anglosajón. Vniversitas, (118), 247-271.

Vigo, R. (2012). Constitucionalización y judicialización del derecho: del Estado de Derecho Legal al Estado de Derecho Constitucional. Pontificia Universidad Javeriana; Grupo Editorial Ibáñez. 